\title{
correspondence
}

\section{No Two Alike?}

\section{Nancy C. Knight ${ }^{1}$}

One of the most quoted statements about snow crystals is that no two are alike, a bit of folk wisdom that is generally accepted even among those few regarded as experts in the subject, although, in the interests of precision, the latter are more likely to substitute "identical", for "'alike." Figure 1, a photograph of actual snow crystals, not replicas, illustrates a striking example of two snow crystals which, if not identical, are certainly very much alike. The crystals were collected on a glass slide coated with oil and exposed at the end of a rod extended from an aircraft. The slide on which the crystals were collected was exposed for eleven seconds from the NCAR King Air flying between two layers of cirrus cloud over Wausau, Wisconsin, during the NASA First ISCCP (International Satellite Cloud Climatology Project) Regional Experiment (FIRE). During the exposure the mean altitude of the aircraft was $6134 \mathrm{~m} \mathrm{(msl)}$ and the mean temperature was $-22^{\circ} \mathrm{C}$. The King Air was not equipped with a particle decelerator. Its mean true air speed during exposure was 110 meters per second, resulting in shattering of the more-fragile crystals. The crystals of interest, however, in the lower center of the figure, are quite well preserved and unique in the author's experience.

The crystals in this pair are probably best classified as exceptionally thick, hollow columns, C1f (Magono and Lee 1966). The internal, vase-like skeleton structures of the two are virtually identical. Such crystals begin as solid hexagonal prisms and develop the observed structures through complicated responses to temperature, humidity, fall rate, and orientation, described by Frank $(1974,1982)$ as lacunary growth. The term arises from the fact that growth on a crystal face is always faster at the edges of the face than at its center which, under some circumstances of continued growth, leaves a hollow (lacuna) at the center. Because of their form, and because most columnar crystals are observed to have internal structures in which the hollow ends of the columns are fairly symmetrical, they are assumed to fall with their columnar axes horizontal. These characteristics are illustrated by the single columnar crystal also in Fig. 1. The paired crystals are alike in the marked asymmetry of their internal structures. The difference in the ends of the hollow columns suggests a fall orientation in which the columnar axes were vertical and the slightly greater growth of the left halves suggests that they were the lower ends.

Both the nearly perfect side-by-side position of the paired crystals and their similarity indicate that they grew attached together despite the displacement of their growth centers. Although the crystals shown in Fig. 1 are the most-striking examples, there are suggestions of the same phenomenon at the upper left of Fig. 1 and at the lower right of Fig. 2, a photograph of another area of the same slide. Unfortunately these crystals are less-well preserved and in Fig. 2 a third crystal appears to have landed atop the pair.

\footnotetext{
${ }^{1}$ National Center for Atmospheric Research, P.O. Box 3000, Boulder, Colorado 80307-3000. The National Center for Atmospheric Research is sponsored by the National Science Foundation.

(C)1988 American Meteorological Society
}
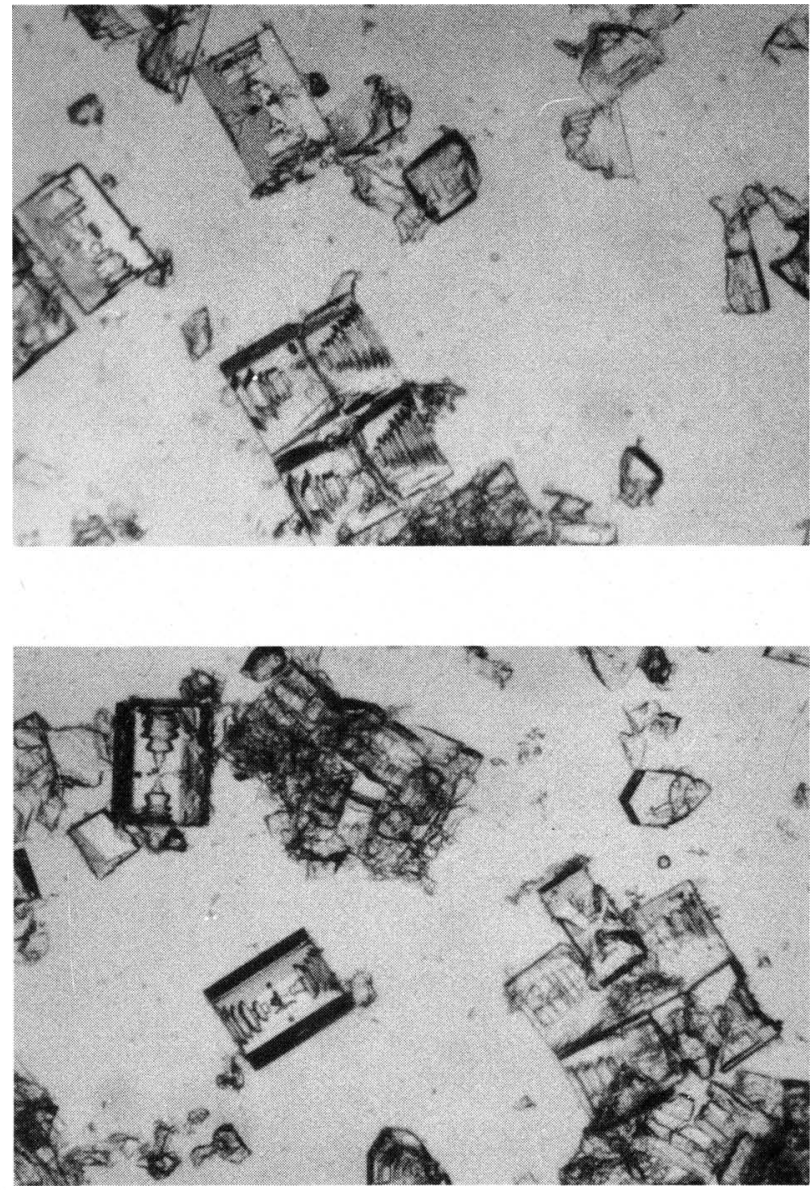

FIG. 2. Same as Fig. 1, same scale.

The scale is the same in both figures where each of the paired crystals in Fig. 1 is $250 \mu \mathrm{m}$ parallel to the columnar axis and $170 \mu \mathrm{m}$ perpendicular to it.

In many years of snow-crystal collection the author has seen no other examples of such crystals nor are any given in the standard references. Charles Knight has suggested a possible mode of growth in which the columnar crystals grew from adjacent tips of a stellar crystal. Such a growth mode would explain the vertical fall orientation, although the complete assemblage would probably have been too fragile to survive aircraft collection intact. This explanation appeals to a snowcrystal form that has never been observed, but no other explanation has been offered for this apparent contradiction of the long-accepted truism that no two snow crystals are alike.

Acknowledgement. The field phase of this experiment was supported by NASA project order \#L-98100B.

\section{References}

Frank, F. C., 1974: Japanese work on snow crystals. J. Crys. Growth, 24/25, 3-5.

Frank, F. C., 1982: Snow crystals. Contemp. Phys., 23, 3-22.

Magono, C., and C. W. Lee, 1966: Morphological classification of natural snow crystals. J. Fac. Sci., Hokkaido Univ., 2, 321-335. 